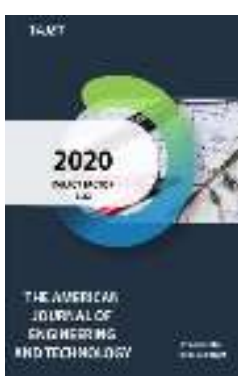

\title{
Cotton Oil Shortenings And Optimal Parameters Of Their Temperature Process

\author{
Sabirova Nargiza Nusratovna
} \\ PhD, Bukhara Engineering-Technological Institute, Bukhara City, Uzbekistan
}

\begin{abstract}
Journal Website: http://usajournalshub.c om/index,php/tajet

Copyright: Original content from this work may be used under the terms of the creative commons attributes 4.0 licence.
\end{abstract}

\section{ABSTRACT}

The tempering properties of shortening of fats based on cottonseed oil and products of its processing were studied. It has been experimentally established that the tempering of hard shortening has several advantages. The tempering temperature is carefully selected to obtain the desired crystal matrix in shortening. In the absence of this step, the crystal structure in the product continues to change with time and temperature during storage and transportation. The consistency of the shortening changes at influence of high or low temperatures even with proper tempering. However, there is always some recovery of consistency when the product returns to its primary storage temperature. Properly tempered shortening shows plasticity over a wider temperature range, as well as storage temperature fluctuations.

\section{KEYWORDS}

Cottonseed oil and products of its processing, shortening of fats, tempering properties, crystal structure, temperature modes

\section{INTRODUCTION}

Fats and shortenings have different types and sizes of solid crystals, which must be mixed before use to form a homogeneous liquid. This process is called fat and shortening tempering and is used primarily in 
many margarine plants. In foreign countries, such fats are made on the basis of solid fats of vegetable origin, in particular, palm and palm kernel oils [1-7]. Shortening fats are used to prepare a wide range of food products [8-10]. The use of cottonseed oil and its processed products for the production of shortenings is of scientific and practical interest. We have proposed [11-12] shortening fats based on the products of catalytic modification of cottonseed oil. In connection with this, the task was set to study the tempering properties of solid shortening fats.

\section{METHODS}

The crystalline structure of fats is determined by melting them at different temperatures. The temperature of shortening fats was measured in ${ }^{\circ} \mathrm{C}$. Modern methods of physical and chemical research were used.

\section{RESULTS AND DISCUSSION}

It has been found experimentally that tempering solid shortening has several advantages. The tempering temperature is carefully selected to obtain the desired crystalline matrix in shortening. In the absence of this step, the crystal structure in the product continues to change with time and temperature during storage and transport. The consistency of shortening changes even when properly tempered, when exposed to high or low temperatures. However, there is always some recovery in consistency when the product returns to its original storage temperature. Correctly tempered shortening exhibits ductility over a wider temperature range as well as fluctuating storage temperatures.

The data in Figure 1-3 illustrate the effect of tempering temperatures on shortening solids. These figures also demonstrate the effect of storage temperature on consistency as well as the ductility of shortening.

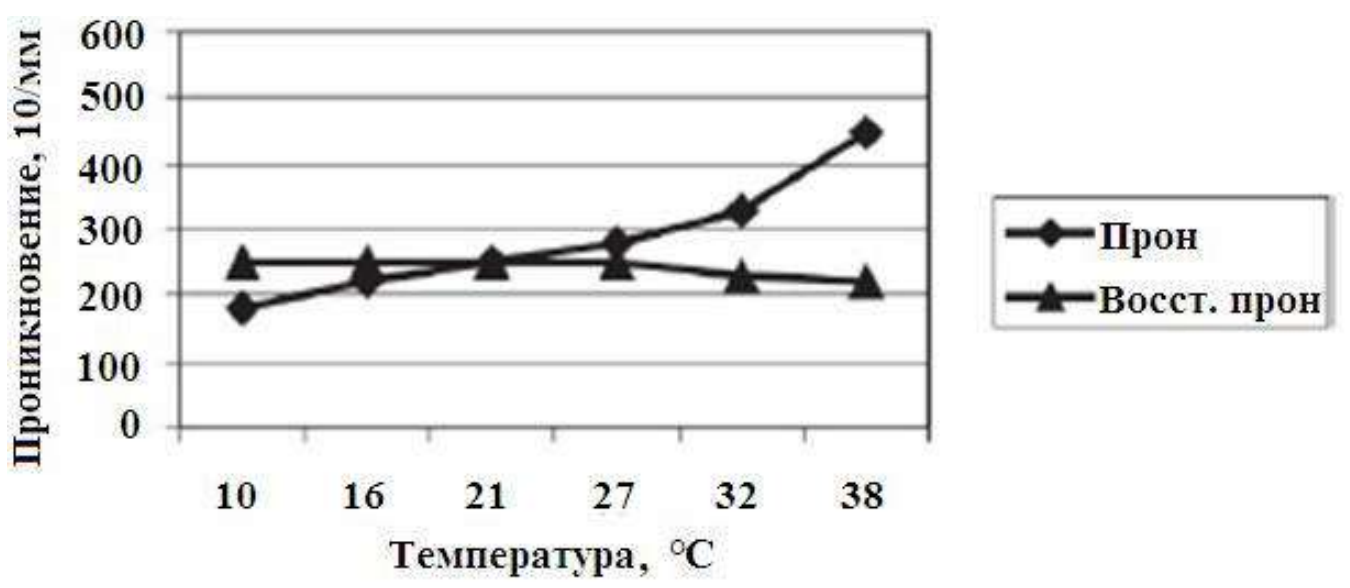

Figure: 1. Tempering at $29^{\circ} \mathrm{C}$ 

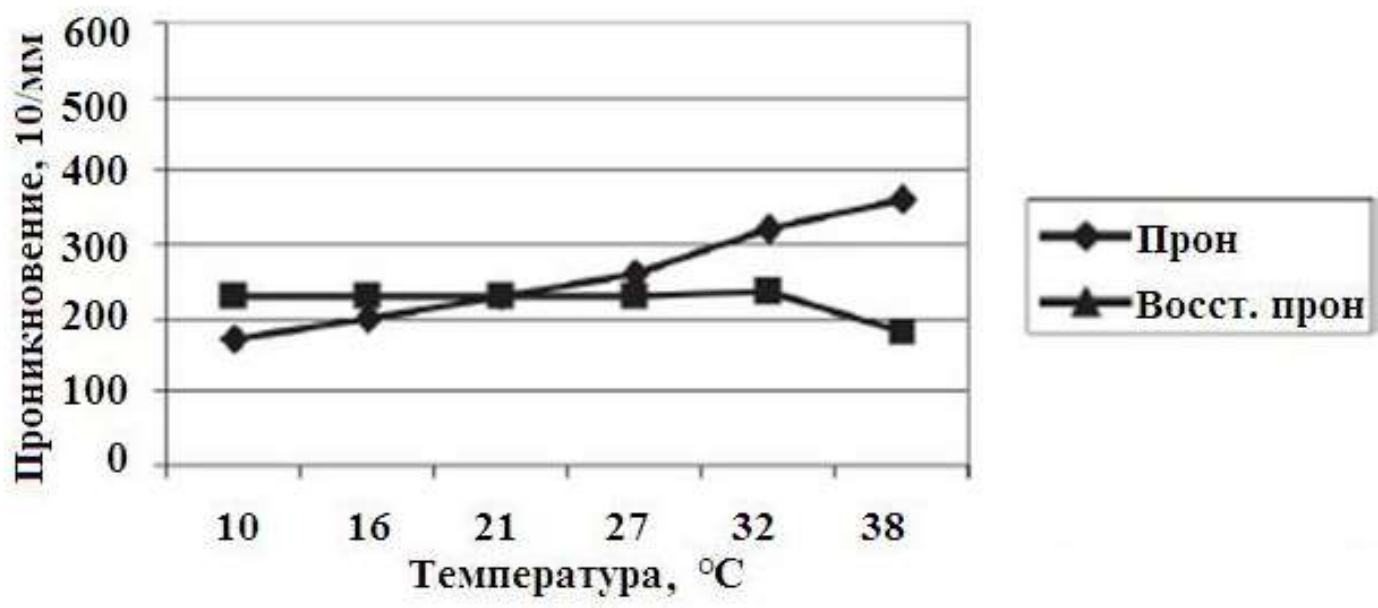

Figure: 2. Tempering at $32^{\circ} \mathrm{C}$

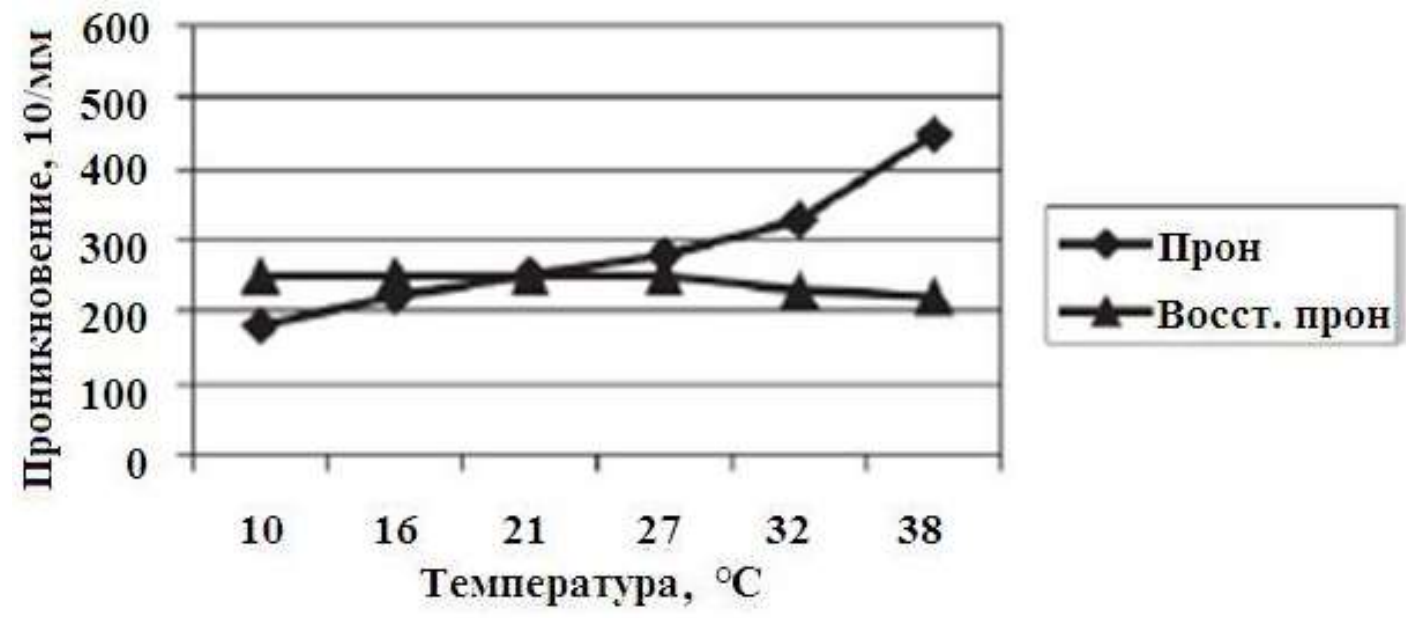

Figure: 3. Tempering at $21^{\circ} \mathrm{C}$

Three temperatures have been chosen for tempering the product:

$29^{\circ}$ C, i.e. average temperature in storage warehouses. $32^{\circ} \mathrm{C}$ and $21^{\circ} \mathrm{C}$ were selected to demonstrate the effect of tempering temperature on the consistency of the same product.

In the studies, the product was kept at $32^{\circ} \mathrm{C}$ temperatures for 48 hours. The products were then left at $10,16,21,27,32$ and $38^{\circ} \mathrm{C}$ overnight to equilibrate at these storage temperatures. Penetrations were measured at various storage temperatures. All product samples were removed from their respective storage facilities and placed at 21
- C overnight for equilibration. Penetrations were measured on all samples. This is referred to as "Penetration Restoration". Penetration and recovery data are shown in Table 1, and graphs are shown in Fig. 1. $\left(29^{\circ} \mathrm{C}\right)$, Fig. $2\left(32^{\circ} \mathrm{C}\right)$ and Fig. $3\left(21^{\circ} \mathrm{C}\right)$.

Compared to the sample tempered at $29^{\circ} \mathrm{C}$, the other samples gave different results.

Tempered at $21^{\circ} \mathrm{C}$ in the sample, the following observations were made.

The sample had a softer consistency (higher penetration values) at all storage temperatures. Penetration recovery indicated that the same sample 
The American Journal of Engineering and Technology

(ISSN - 2689-0984)

Published: October 30, 2020 | Pages: 28-32

Doi: https://doi.org/10.37547/tajet/Volume02Issue10-06

had a shorter plasticity range (penetration recovery

remained flat over a narrower temperature range).

Table 1.

Penetration and Penetration Recovery Data for shortening tempered at different temperatures

\begin{tabular}{|c|c|c|c|c|c|c|}
\hline \multirow[t]{2}{*}{ Temperature, ${ }^{\circ} \mathrm{C}$} & \multicolumn{2}{|c|}{ Tempered at $21^{\circ} \mathrm{C}$} & \multicolumn{2}{|c|}{ Tempered at $29^{\circ} \mathrm{C}$} & \multicolumn{2}{|c|}{ Tempered at $32^{\circ} \mathrm{C}$} \\
\hline & 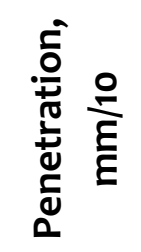 & 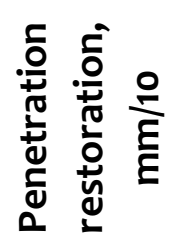 & 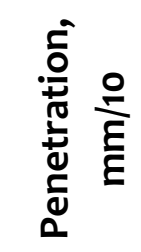 & 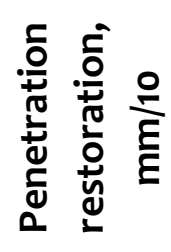 & 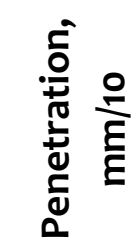 & 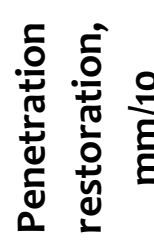 \\
\hline 10 & 230 & 300 & 180 & 250 & 170 & 230 \\
\hline 16 & 270 & 300 & 220 & 250 & 200 & 230 \\
\hline 21 & 300 & 300 & 250 & 250 & 230 & 230 \\
\hline 27 & 350 & 270 & 280 & 250 & 260 & 230 \\
\hline 32 & 420 & 250 & 330 & 230 & 320 & 235 \\
\hline 38 & 540 & 220 & 450 & 220 & 360 & 180 \\
\hline
\end{tabular}

The numbers in the table represent penetration and penetration recovery at $21^{\circ} \mathrm{C}$. This is because $21^{\circ} \mathrm{C}$ is a significant temperature for shortening storage and use times.

The sample tempered at $32^{\circ} \mathrm{C}$ had a harder consistency (lower penetration values) at all storage temperatures. Penetration recovery indicated that the same sample had a shorter plasticity range (penetration recovery remained flat over a narrower temperature range).

The possibility of using cottonseed and soybean oils and their hydrogenation products for obtaining shortening fats resistant to oxidation during their long-term storage is shown. It was found that tempering the fat mixture prior to its crystallization makes it possible to increase the proportion of homogeneous crystals that provide the plasticity of the shortening fats obtained.

\section{CONCLUSION}

Thus, the sample tempered at $21^{\circ} \mathrm{C}$ had a softer consistency (higher penetration values) at all storage temperatures. The sample tempered at $32^{\circ} \mathrm{C}$ had a harder consistency (lower penetration values) at all storage temperatures.

\section{REFERENCES}

1. Stopskiy V.S., Klyuchkin V.V., Andreev N.V. Khimiya zhirov i produktov pererabotki zhirovogo syrya [Chemistry of fats and fat stock processing products]. - M.: Kolos, 1992. $286 \mathrm{p}$. 
2. Grinberg G., Schepanskaya G. Modifitsirovannye zhiry [Modified fats]. - M.: Food industry, 1973.104 p.

3. Haumann. B. R. The goal, tastier and «healthier» fried foods // INFORM, 1996, 7, pp.320-334.

4. O'Brien, R.D.Shortening technology // Introduction to Fats and Oils Technology / O'Brien, R.D., Fair, W.E., Wan, P.J., eds.-2nd ed.-Champaign, IL:AOCS Press, 2000.pp.422426.

5. Oil Crops Situation and Outlook Yearbook/USDA.-Washington, D.C.:U.S. Department of Agriculture Economic Research Service, 1985.

6. Oil Crops Situation and Outlook Yearbook/USDA.-Washington, D.C.:U.S. Department of Agriculture Economic Research Service, 2000.50 p., 63.

7. Haumann, B.F. The goal: tastier and "healthier" fried foods//INFORM, 1996, 1, pp.320-334.

8. Weiss, T.J. Shortening: introduction // Food Oils and Their Uses-2nd ed.-Westport, CN: AVI Publishing, 1983. pp.129-130.

9. Paulicka, F.R. Shortening products // Edible Fats and Oils Processing: Basic Principles and Modern Practices, Word Conference Proceedings / Erickson, D.R., ed.-Champaign, IL: AOCS Press, 1990. pp.205-206.

10. Stauffer, C.E., Bakery product applications // Fats and Oils / Stauffer. C.E., ed.-St. Paul, MN: Eagan Press, $1996.73 \mathrm{p}$.

11. Sabirova N.N., Majidov K.X., Characteristics of new kinds of shortenings. - Austrian Journal of Technical and Natural Sciences, 2018, no. 11 12, pp.16-19.

12. Sabirova N.N., Mazhidov K.Kh. Development of the composition and study of the characteristics of new types of shortenings // Uzbek Chemical Journal. 2018, no. 6, pp.5862. 